\title{
Sensory characteristics of human milk: Association between mothers' diet and milk for bitter taste
}

\author{
Dimitra Mastorakou, ${ }^{1,2}$ Angelica Ruark, ${ }^{1,2}$ Hugo Weenen, ${ }^{1 *}$ Bernd Stahl, ${ }^{1}$ and Markus Stieger ${ }^{2}$ \\ ${ }^{1}$ Danone Nutricia Research, Uppsalalaan 12, 3584 CT Utrecht, the Netherlands \\ ${ }^{2}$ Wageningen University, Division of Human Nutrition, P.O. Box 17, 6700 AA Wageningen, the Netherlands
}

\section{ABSTRACT}

It is unknown how consumption of bitter foods and beverages in the maternal diet influences sensory properties of fresh human milk. The aims of this study were (1) to determine the sensory characteristics of fresh human fore and hind milk, (2) to establish relationships between sensory properties and composition of fresh human milk, and (3) to assess the relationship between bitterness of the maternal diet and human milk. Twenty-two lactating mothers generated sensory terms to describe perception of their milk and received training on sensory attribute intensity rating. Mothers kept a $24-\mathrm{h}$ food diary followed by a sensory self-assessment of their fore and hind milks. The odor of human fresh milk was described as neutral, creamy, and sweet, taste as sweet and bitter, and mouthfeel as thin, watery, smooth, and fatty. Sweetness was equivalent to $1.53 \mathrm{~g}$ of sucrose/100 $\mathrm{mL}$ and was not significantly different between fore and hind milk. Fore milk was significantly less creamy, less fatty, thinner, more watery, and lower in vanilla flavor intensity than hind milk. Carbohydrate content of human milk was positively correlated with sweetness and glutamic acid content with umami. The bitterness of the diet consumed $24 \mathrm{~h}$ before lactation was moderately positively correlated with bitterness of fore milk, but not hind milk. We conclude that the consumption of bitter foods may influence the bitterness of human fore milk, which may be another way for breastfed children to learn to accept bitter vegetables and, hence, develop healthier food preferences.

Key words: breastfeeding, human milk, sensory perception, bitterness, maternal diet

\section{INTRODUCTION}

Consuming a varied and healthy diet over a lifetime can provide adequate amounts of nutrients essential for

Received July 6, 2018.

Accepted October 17, 2018.

*Corresponding author: hugo.weenen@danone.com growth and development and prevent malnutrition and noncommunicable chronic diseases (WHO/FAO, 2002). For infants, human milk is the ideal form of nutrition for growth and development in their first years of life, as it provides a variety of bioactive components that are beneficial for infant health (Ballard and Morrow, 2013). In later life, a varied and balanced diet in agreement with nutritional recommendations is often not fully achieved by children. Especially regarding fruit and vegetable intake, US and European children are far from reaching the recommended dietary guidelines (Yngve et al., 2005; van Rossum et al., 2009). The limited acceptance of vegetables has been suggested to trace back to our evolution. Humans reject bitter foods to avoid toxic compounds commonly found in plants (Ames et al., 1990; Drewnowski, 1997; Drewnowski and Gomez-Carneros, 2000). This immutable instinctive rejection for bitter foods has been important for human survival. Rejection of bitterness is observed in many species, including goats, sheep, and cattle (Goatcher and Church, 1970). Especially in children, taste can often drive food preference and choice (Drewnowski, 1989, 2000). Early-life flavor experiences and eating behavior can influence food preference and choice in child- and adulthood (Lytle et al., 2000; Lien et al., 2001; Skinner et al., 2002; Nicklaus et al., 2005; Cooke and Fildes, 2011; Nehring et al., 2015); therefore, the challenge of increasing children's vegetable consumption should start early in life.

Infants experience flavors of foods for the first time by the transmission of dietary volatiles from their mothers' diet to the amniotic fluid and breast milk (Mennella, 2007). During the first 4 mo of life, breastfeeding confers a greater acceptance of these foods, particularly when they are part of the mother's diet (Sullivan and Birch 1994; Mennella et al., 2001). The more varied the mother's diet is during lactation, the more varied the flavor of her milk (Mennella, 2007); this could explain why children who were breastfed are less picky and more willing to try new foods as they grow compared with children who were fed formula (Galloway et al., 2003). A recent study showed that drinking carrot 
and broccoli juice during breastfeeding increased the infant's acceptance of carrot-flavored cereal several months later, but did not affect acceptance of broccoliflavored cereal (Mennella et al., 2017). Consistent with this is that duration of breastfeeding was shown to be a predictor of vegetable intake (de Wild et al., 2018).

Human milk (Buettner, 2007), as well as bovine milk (Toso et al., 2002; MacGibbon and Taylor, 2006), contain odorants from various chemical categories, including fatty acids, aldehydes, terpenoids, and ketones. Transference of flavor compounds through maternal milk has been shown as early as the 18th century (Bradley, 1757; Babcock, 1938; Shipe et al., 1978). Volatile components, such as 1,8-cineole (Kirsch et al., 2013), D-carvone, trans-anethole, L-menthol (Hausner et al., 2008), vanillin (Mennella, and Beauchamp, 1996a), garlic (Mennella and Beauchamp, 1991a), carrot flavor volatiles (Mennella, and Beauchamp, 1999), ethanol (Mennella, and Beauchamp, 1991b), volatiles from cigarettes (Mennella and Beauchamp, 1998), and caffeine, theobromine, paraxanthine, theophylline, and nicotine (Aresta et al., 2005), have been shown to be transmitted to human milk.

As far as we know, the sensory characteristics of fresh cow milk as well as cow fore and hind milk have not been reported. Instead, most studies on the sensory characteristics of cow milk (for review see Schiano et al., 2017) have focused on the effect of fat content (McCarthy et al., 2017), various ways of preservation (Lee et al., 2017), off-flavors (Alvarez, 2008), and changes over shelf-life (Fromm and Boor, 2004). Attributes that have been listed as relevant for milk include sweet aroma, cooked, sulphury/eggy, milk fat/lactone, caramelized, butterscotch, feed/malty/silage, grassy, cowy/ barny/phenolic, metallic/serum, fruity, cardboard, carroty, sweet taste, bitter taste, astringent, and viscous. To the best of our knowledge, and in contrast to numerous studies describing sensory properties of processed bovine milk (for review see Schiano et al., 2017), only one study has been reported describing the in-mouth sensory properties of human milk based on a trained sensory panel (McDaniel et al., 1989). In that study, fore and hind milks expressed on 3 consecutive days by 24 mothers were compared for a limited number of sensory attributes (sweetness, viscosity, and mouth coating) using a trained panel consisting of 6 women. In their study, fore milk was defined as approximately the first $30 \mathrm{~mL}$ expressed from the first breast before the infant was nursed, whereas hind milk was approximately the final $30 \mathrm{~mL}$ expressed from the first breast after the infant was removed from the breast. Differences in sweetness among milks obtained on different days from the same mother were observed in that study. Viscos- ity and mouth coating of milks obtained on different days from the same mother did not differ. Hind milk was more viscous than fore milk, as shown from both sensory evaluation and rheological measurements. Hind milk was more mouth-coating and had a lower lactose concentration than fore milk. The difference in lactose concentration between fore and hind milk was $0.2 \%$ (wt/wt) and was considered too small to cause a difference in sweetness. Fat content of milks ranged from 0.57 to $4.12 \mathrm{~g} / 100 \mathrm{~mL}$. Hind milk had a significantly higher fat content than fore milk. Protein content ranged from 0.63 to $2.15 \mathrm{~g} / 100 \mathrm{~mL}$ and hind milk contained significantly more protein than fore milk. In comparison, Mitoulas et al. (2002) found significant differences in fat content between fore and hind milk throughout the first year of lactation and no significant differences in protein and lactose content. Two other studies reported sensory profiles of fresh and stored frozen human milk (Spitzer et al., 2010) and after storage at $4^{\circ} \mathrm{C}$ (Spitzer et al., 2013). A panel evaluated orthonasal intensities of odor attributes and found these to be very low for fresh human milk (Spitzer et al., 2010). Five untrained mothers evaluated the in mouth intensities of 11 aroma attributes using their own milk. Aroma attributes with a mean intensity rating of 2 (3-point scale) included sweet, fatty, soya-like, whereas those with a mean intensity rating of 1 included buttery and cooked milklike (Spitzer et al., 2010).

Another study compared human milks of mothers with mastitis and noninflamed breasts. Taste intensities measured with an instrumental taste sensor (SA402B E-tongue sensor, Higuchi, Tokyo, Japan) significantly correlated with composition of milks, specifically instrumentally determined sourness correlated positively with lactose content, instrumentally determined saltiness with lactose (positive) and calcium content (positive), and instrumentally determined bitterness with calcium content (negative), urea content (positive) and pH (negative; Yoshida et al., 2014).

To summarize, sensory characteristics of human breastmilk can be influenced by maternal diet and can contribute to shaping an infant's and child's acceptance of foods. In contrast to numerous studies on the effect of feed on the composition of bovine milk (e.g., Sutton, 1989; Palmquist et al., 1993), detailed understanding is lacking about the influence of the maternal diet on taste and sensory properties of human milk and how the diet can be altered to influence children's food preferences. Sensory properties of fresh human milk have been described by only 2 studies: one study used a trained panel and assessed only 3 sensory descriptors, whereas another study was based on the self-assessment of human milk by untrained mothers 
and did not distinguish between fore and hind milk (Spitzer et al., 2010). Hence, knowledge about sensory properties of fresh human fore and hind milk is very limited. A particularly interesting question is how the bitterness of the maternal diet influences bitterness perception of human milk, as this might be relevant for development of acceptance of vegetables by children. Previous studies using hydrolyzed formulas (Mennella and Beauchamp, 1996b) have shown that bitter taste is relatively well accepted in the first few months of life. Repeated exposure to bitter-tasting hydrolyzed formula increases acceptance of formula. This raises the question how the maternal diet affects bitterness of human milk and how this affects acceptance of bitter foods, such as vegetables, later in life. Research by Aresta et al. (2005) has shown that bitter-tasting alkaloids can be transferred from the maternal diet to milk; thus, we expected that the maternal diet may affect bitterness of human milk. Nevertheless, this has not been reported. The aims of our study were (1) to determine the sensory characteristics of human fore and hind milk, (2) to establish relationships between sensory properties and composition of human milk, and (3) to assess the relationship between bitterness of the maternal diet and bitterness of human milk.

\section{MATERIALS AND METHODS}

\section{Subjects}

Twenty-two nonsmoking, breastfeeding, apparently healthy volunteer mothers aged 28 to $43 \mathrm{yr}$ participated in the study. The minimum number of subjects had been set at 20, as in a previous pilot study a significant correlation between bitterness of the maternal diet and resulting milk was found in a sample of 10 mothers; therefore, a minimum of 20 mothers was assumed to be sufficient to detect or confirm such a correlation. Mothers were recruited via posters at various locations in the Utrecht Science Park (Utrecht, the Netherlands) or with the assistance of OP\&P (Utrecht, the Netherlands). Selection criteria were that mothers were breastfeeding for at least $1 \mathrm{mo}$ until $12 \mathrm{mo}$ and produced adequate milk. Before the start of the study, a pilot study was performed with 2 mothers to ensure the study design was appropriate. The results of the pilot study are not included in the data analysis. All mothers were informed about the procedures before the study and signed an informed consent form. The study was conducted according to the guidelines laid down in the Declaration of Helsinki. The project proposal, including questionnaires, advertisement, and consent form were submitted to an accredited Medical Research Ethics
Committee (Independent Review Board, Nijmegen, the Netherlands), which confirmed that the study did not require review by an ethical committee according to Dutch law (reference number IRBN2016003 HdJ 1). The demographics of the 22 mothers who participated in both sessions were collected through the use of a questionnaire that the mothers filled in before session 2 . Three mothers who initially participated in the first session were unable to participate in the second session due to low milk supply.

\section{Study Design}

Participants were requested to arrive at the research center at the same time in the afternoon on $2 \mathrm{~d}$, to participate in sessions of 60 to $90 \mathrm{~min}$. During the first session, mothers became familiarized with the 5 basic taste modalities (sweet, salty, bitter, sour, and umami) and creaminess using reference samples with varying levels of intensity. Mothers generated sensory terms to describe odor, flavor, and mouthfeel of their own milk. In the second session, mothers evaluated their fore and hind milk on various sensory characteristics. Analytical measurements were conducted for fore and hind milk to quantify fat, carbohydrate, total protein, and free AA content. Between the 2 sessions, a 24-h food diary was kept by the mothers to assess the bitterness of the maternal diet.

\section{Procedure}

General. The study consisted of 2 sessions performed either in the discussion room of the sensory laboratory at Nutricia Research, Utrecht, the Netherlands, or at the homes of the mothers. Mothers were instructed not to wear any perfumes or use any strongly scented soaps or deodorants on testing days. They were also instructed not to eat or drink anything (except water) and not to express milk an hour before the session. All samples (reference solutions for sensory testing and human milk samples) were coded with 3 digits and presented in a randomized block design. All samples for sensory testing were kept in 50 -mL glass vials and heated to approximately $40^{\circ} \mathrm{C}$ using a test-tube rack (VWR, Radnor, PA) in a water bath at Nutricia Research or in bottle warmers (Topcom, Leuven, Belgium) if conducted at home. All documents were available in Dutch and English to allow mothers to choose their preferred language for the study.

Preparation of Reference Solutions. Reference solutions were prepared for the evaluation of basic taste intensities and creaminess. The concentrations used for the reference solutions are listed in Table 1. Sucrose 
Table 1. Concentrations of reference solutions used during sensory evaluations of human fore and hind milk by the 22 mothers ${ }^{1}$

\begin{tabular}{|c|c|c|c|}
\hline Attribute & Substance & $\begin{array}{l}\text { Concentration } \\
(\% \mathrm{wt} / \mathrm{wt})\end{array}$ & $\begin{array}{c}\text { Recognition threshold } \\
(\% \mathrm{wt} / \mathrm{wt})\end{array}$ \\
\hline Sweet & Sucrose & $\begin{array}{l}\text { First: } 1.06 \\
\text { Second: } 2.12^{2} \\
\text { Third: } 4.24\end{array}$ & $0.121,0.576$ \\
\hline Salty & Sodium chloride & $\begin{array}{l}\text { First: } 0.032 \\
\text { Second: } 0.080 \\
\text { Third: } 0.200^{2}\end{array}$ & $0.046,0.119$ \\
\hline Sour & Citric acid & $\begin{array}{l}\text { First: } 0.009 \\
\text { Second: } 0.022 \\
\text { Third: } 0.056^{2}\end{array}$ & $0.012,0.028$ \\
\hline Bitter & Caffeine & $\begin{array}{l}\text { First: } 0.009 \\
\text { Second: } 0.022 \\
\text { Third: } 0.054^{2}\end{array}$ & $0.011,0.020$ \\
\hline Umami & Monosodium glutamate & $\begin{array}{l}\text { First: } 0.024 \\
\text { Second: } 0.060 \\
\text { Third: } 0.151^{2}\end{array}$ & $0.013,0.029$ \\
\hline Creamy & Milk fat & $\begin{array}{l}\text { First: } 1.6 \\
\text { Second: } 4.0^{2} \\
\text { Third: } 10.0\end{array}$ & $\mathrm{NA}^{3}$ \\
\hline
\end{tabular}

${ }^{1}$ Estimated recognition thresholds for all taste modalities are shown. Recognition thresholds were calculated based on (first value) Hoehl et al. (2010) and (second value) ISO (2011).

${ }^{2}$ Solutions used as reference during session 2 .

${ }^{3} \mathrm{NA}=$ data not available in the literature.

(Suiker Unie, Oud Gastel, the Netherlands), sodium chloride (Akzo Nobel Industrial Chemicals B.V., Arnhem, the Netherlands), monosodium glutamate (Corimex Unilever, Rotterdam, the Netherlands), caffeine (Sigma-Aldrich, St. Louis, MO), and citric acid (Merck KGaA, Darmstadt, Germany) were used to prepare sweet, salty, umami, bitter, and sour solutions, respectively. Creamy reference emulsions were prepared by mixing semiskim milk (Friesland Campina, Amersfoort, the Netherlands; $1.5 \%$ fat) with whipping cream (Friesche Vlag, Friesland Campina; $35.1 \%$ fat), both purchased from local supermarkets. Evian water (Danone, Paris, France) was always used with the exception of sour solutions, which were prepared with demineralized water. Taste solutions and creamy emulsions were transferred into $50-\mathrm{mL}$ glass vials and placed in a water bath at $40^{\circ} \mathrm{C}$. Basic tastes have been shown to follow Fechner's law, meaning a semi-logarithmic relationship between tastant concentration and perceived intensity holds (Yamaguchi, 1998). As shown in Table 1, concentrations of taste solutions varied by a factor of $2.5 \times$ for all taste modalities except sweetness, for which a factor of $2 \times$ was used. For bitter, sour, salty, and umami an equi-intensity of 2.5 of the Spectrum scale, as obtained from the study of Martin et al. (2015), was placed at $75 \%$ of the $100-\mathrm{mm}$ line scales that were provided for the rating tasks. The concentrations of the references for bitter, sour, salty, and umami were based on Martin et al. (2015) and were equi-intense. If we had followed the same systematics for sweet, the sucrose concentra- tion for the $75 \%$ point on the $100-\mathrm{mm}$ line scales should have been $73.1 \mathrm{~m} M$, which is $2.5 \mathrm{~g} / 100 \mathrm{~mL}$. However, the concentration at the $75 \%$ point that we used was $4.24 \mathrm{~g} / 100 \mathrm{~mL}$. The references for sweetness were different, as they were selected based on the expected sweetness following McDaniel et al. (1989). The expected mean sweetness of the human milk samples was $2.12 \mathrm{~g} / 100 \mathrm{~mL}$; therefore, the concentration of the $50 \%$ mark reference sample for sweet had this concentration to avoid ceiling effects. When sensory evaluations by the mothers were performed at home, all solutions were stored in bottle warmers at $40^{\circ} \mathrm{C}$.

Session 1: Attribute Generation and Training of Mothers. The first session consisted of 3 parts: breastmilk expression, generation of sensory attributes to describe human milk by the mothers, and training of the mother to assess basic taste and creaminess intensity. All 22 mothers were provided with a questionnaire upon entering the research room.

The mothers were first requested to express at least $50 \mathrm{~mL}$ (or as much as they could provide) of milk in their usual way, using their own pump and filling their usual bottles. The mothers were given privacy to express their milk. The mothers were asked to indicate whether they were pumping from a single breast or both and how many times they pumped or breastfed that day. The milk was then handed to the researcher who transferred the milk into a $50-\mathrm{mL}$ glass vial and placed it in the water bath with the standard solutions at $40^{\circ} \mathrm{C}$. 
Approximately $10-\mathrm{mL}$ of their own milk was poured into a plastic cup for the mother to evaluate. Mothers were first asked to smell the milk and write down as many sensory attributes as possible to describe the odor perception. Mothers were then asked to do the same for flavor and mouthfeel perception of her milk. For both elicitation tasks, mothers were instructed to generate objective terms and avoid subjective terms or opinions. After $5 \mathrm{~min}$, mothers had usually completed the free term-elicitation task. Mothers were then presented with a list of attributes from studies on infant formula sensory characteristics (van Ruth et al., 2006) and previous research conducted at Nutricia (M. Slagter, Danone Nutricia Research, Utrecht, the Netherlands, personal communication). The list of provided attributes can be found in Table 2. From this list, mothers could select additional terms that described their own milk. The purpose of this task was to facilitate term elicitation for mothers that had not tasted their milk before. No definitions were provided for sensory attributes.

After the attribute-elicitation task, mothers underwent a training session to familiarize themselves with the 5 basic taste modalities (sweet, sour, salty, bitter, and umami) and creaminess. During the training, all references solutions (Table 1) were provided together with 100-mm line scales anchored at the end of the scale with "like water" ("like milk" for creamy) and "strong." Mothers tasted 3 reference solutions differing in concentration for each taste modality and creaminess (Table 1). Mothers were instructed to first rank the 3 reference solutions in order of increasing intensity and then evaluate perceived taste intensity on $100-\mathrm{mm}$ line scales. Mothers used the relative-to-reference method to perform the line scale intensity rating, rating 2 intensities in comparison to a third (Stoer and Lawless, 1993). When mothers did not rank the reference solutions in the right order, the correct order was shown and mothers retasted the solutions to ensure they understood the correct ranking order.

Between Session 1 and Session 2: 24-h Food Diary and Bitterness of Maternal Diet. During the 24-h period between the first and second session, mothers filled in a food diary. For this, mothers were provided with a kitchen scale (Soehnle, Nassau, Germany) and a piece of $85 \%$ cacao chocolate (Lindt Excellence Series, Lindt \& Sprüngli, Zürich, Switzerland) at the end of session 1. Mothers tasted the chocolate $48 \mathrm{~h}$ before the second session and provided a score for bitterness intensity of the chocolate on a scale from 0 to $10(0=$ not bitter at all, $10=$ most bitter $)$ in an open box on the food diary. Mothers recorded their diet for the 24 -h period between session 1 and 2 by capturing the time of consumption, description of food or drink
Table 2. List of descriptive sensory attributes provided to mothers during the attribute elicitation task for human milk ${ }^{1}$

\begin{tabular}{lll}
\hline Smell & Flavor & Mouthfeel \\
\hline Burned & Sweet & Thick \\
Creamy & Bitter & Smooth \\
Metallic/iron & Salty & Creamy \\
Wet soil & Sour & Coating \\
Cheesy & Umami & Dry \\
Vegetable-like & Vanilla & Slimy \\
Cooked & Caramel & Rough \\
& Burned milk & Powdery \\
& Vegetable oil & Fatty \\
& Metallic & Thin \\
& Fishy & Watery \\
\hline
\end{tabular}

${ }^{1}$ Attributes were derived from the study of M. Slagter (Danone Nutricia Research, Utrecht, the Netherlands, personal communication) and literature (van Ruth et al., 2006).

consumed, brand name, amount in grams, milliliters, or common household measurements (slice, spoon, and so on), and indicated the bitterness score for each product on the 0 to 10 scale relative to the score given for the $85 \%$ cacao chocolate (Deterre et al., 2012). Foods were assessed as eaten (e.g., a sandwich was evaluated as a whole, not as the individual components). For those items that were not weighed with a kitchen scale, approximations for weight were made based on a database (CalorieLab, 2016). The photographs that mothers took of their consumed foods were used to check the 24-h food diaries for completeness.

Session 2: Assessment Session. The second session consisted of 4 parts: expression of fore and hind milk, review of 24-h food diary, sensory evaluation of fore and hind milk by the mothers on basic taste and creaminess intensity relative to reference taste and creaminess solutions, and intensity evaluation of own fore and hind milks on odor, flavor, and mouthfeel attributes.

Mothers were first instructed to express at least 30 $\mathrm{mL}$ of fore milk and $30 \mathrm{~mL}$ of hind milk in their usual way, using a pump and filling up their usual bottles. For those unfamiliar with the definition of fore and hind milk, mothers were instructed to collect the first $30 \mathrm{~mL}$ of their milk and consider this fore milk. The remaining milk that was expressed was considered hind milk. Mothers were asked to use 1 breast, and they informed the researcher which breast was used. The mothers were given privacy to express their milk. The 2 milk samples were then handed to the researcher who transferred the milks into glass vials and placed them in a water bath at $40^{\circ} \mathrm{C}$. For chemical analysis, $6 \mathrm{~mL}$ of fore and $6 \mathrm{~mL}$ of hind milk were placed in the refrigerator $\left(4^{\circ} \mathrm{C}\right)$ to be analyzed immediately after the end of the session for fat, protein, and carbohydrate content; 
$0.5 \mathrm{~mL}$ of each milk was placed in $\mathrm{a}-20^{\circ} \mathrm{C}$ freezer to be analyzed for free AA content.

Following the milk expression, mothers reviewed their 24-h food diaries with the researcher for clarification. Mothers then assessed taste and creaminess intensity of their fore and hind milks relative to reference taste and creaminess solutions (references used in session 2 are indicated with asterisks in Table 1) using unstructured 100-mm line scales anchored at the ends with "like water" ("like milk" for creamy) and "strong."

Finally, mothers evaluated their fore and hind milks on smell, flavor, and mouthfeel attributes generated during the first session using 100-mm line scales anchored with "not at all" and "extremely." The odor attributes evaluated were sweet, milk, and creamy, the flavor attribute was vanilla, and the mouthfeel attributes were thin, watery, fatty, dry, and smooth. This attribute list was compiled from the first 7 mothers who completed the first session and 2 mothers from the pilot test.

Analytical Measurements. Fat, carbohydrate, total protein, energy, TS (fat, protein, carbohydrates, and minerals), and free AA content was analyzed. Determination of fat, carbohydrate, total protein, and TS content and energy was conducted using infrared analysis (MIRIS Human Milk Analyzer, Mid-IR, Uppsala, Sweden). The MIRIS analyzer is based on midinfrared transmission spectroscopy. The transmission values obtained from human milk were converted to concentrations using various calibrations. The MIRIS was calibrated at every start-up of the instrument and after every 10 measurements according to the MIRIS standard procedure (www.mirissolutions.com) using a standard solution that does not contain any macronutrients (MIRIS check solution). This way of analysis has been shown to be precise and accurate when compared with reference methods (Fusch et al., 2015). The free AA content was determined using HPLC using a precolumn derivatization with $o$-phthaldialdehyde and fluorimetry as detection (Brown and Hartwick, 1988).

\section{Data Analysis}

For the selection of attributes to describe human milk, a frequency table of all attributes generated and selected by 22 mothers in the first session was made (Table 3). For the translation of the perceived sweetness of fore and hind milk into sucrose concentration, linear regression lines were derived for each mother individually relating sweetness intensity of the 3 sucrose reference solutions to the concentration of the sucrose reference solutions. Then sweetness intensity of fore and hind milks assessed by mothers in session 2 was expressed as concentration of sucrose in water.
Paired 2-sample $t$-tests were performed to compare fore and hind milk on the basic tastes, creaminess, odor, flavor, and mouthfeel attributes intensity. Unpaired 2 -sample $t$-tests were performed to compare fore and hind milk on analytical measurements of fat, carbohydrates, total protein, and TS content. To assess whether basic taste intensities differed significantly among each other, a mixed model analysis was performed, which included taste (bitter, umami, sour, or salty) and product (fore or hind milk) as fixed factors (as we were interested in taste differences between products), mother as random factor (as milk samples from mothers were expected to be different, but we wanted to focus on the differences between the mean taste values per product), and the taste $\times$ product interaction (as there may be interaction effects). Pairwise comparisons between the 4 taste modalities were performed with Tukey's HSD test. Sweet was not included in the comparison, as bitter, umami, sour and salty had comparable scales, based on the Spectrum references (Martin et al., 2015), whereas the sweetness scale was different (as explained in the Preparation of Reference Solutions section).

Pearson correlations were calculated between sensory attributes of fore and hind milk and composition (fat, carbohydrate, total protein, free AA, and glutamic acid content). Correlations were calculated for selected demographics and composition of milks. In case a significant correlation could be due to an outlier that was visually observed from the scatterplots, the outlier was removed and correlation analysis was performed again to check if the correlation would remain significant. This was the case for the correlations between carbohydrate and glutamic acid contents of one mother, as the contents of these 2 ingredients for this mother turned out to be much lower than for all other mothers. Pearson correlations were also calculated between perceived bitterness of fore and hind milk and bitterness load of the mothers' diets.

For the calculation of bitterness load of the diet, a relative bitterness score was first calculated for the foods consumed by the mother by dividing the bitter-

Table 3. Frequency with which attributes were mentioned by the 22 mothers to describe their milk (only attributes mentioned at least $5 \times$ are listed)

\begin{tabular}{lll}
\hline Odor & Flavor & Mouthfeel \\
\hline Neutral (15) & Sweet (20) & Thin (15) \\
Creamy (10) & Bitter (9) & Watery (13) \\
Sweet (10) & Vanilla (7) & Creamy (10) \\
Milk (9) & Watery (5) & Smooth (10) \\
& & Fatty (9) \\
& & Coating (5) \\
& & Liquid (5) \\
\hline
\end{tabular}


Table 4. Demographics of the 22 mothers who participated in both sessions (mean $\pm \mathrm{SD}$; range)

\begin{tabular}{llc}
\hline Item & Category & Value \\
\hline Age $(\mathrm{yr})$ & & $33.5 \pm 3.8 ; 28-43$ \\
BMI $\left(\mathrm{kg} / \mathrm{m}^{2}\right)$ & & $23.8 \pm 5.2 ; 18.6-38.8$ \\
Parity & Primiparous & 9 \\
& Multiparous $(2$ children $)$ & 13 \\
Ethnicity & Caucasian & 19 \\
& Other & 3 \\
Lactation stage (wk) & & $23.5 \pm 11.3 ; 6-44$ \\
Age of child (mo) & & $5.7 \pm 2.7 ; 1.5-11$ \\
Breastfeed times per day & Yes & $5 \pm 2.3 ; 1-8$ \\
Self-reported change in taste perception & No & 12 \\
& Secondary & 10 \\
Education & Tertiary & 3 \\
& PhD & 16 \\
Working status & Full-time & 3 \\
& Part-time & 13 \\
Tasted human milk before & Not working or $<8 \mathrm{~h} / \mathrm{wk}$ & 6 \\
& Yes & 3 \\
\hline
\end{tabular}

ness score of the food consumed by the bitterness score of the $85 \%$ cacao chocolate reference. This score was multiplied by the amount of food consumed to get the bitterness load per food item. The bitterness load of all foods consumed by the mother during $24 \mathrm{~h}$ was added to obtain the overall bitterness load (in grams) of the diet of the mother. The method used to estimate the bitterness load was a modified version of the method reported by Deterre et al. (2012). Statistical analysis was performed in XLSTAT using a significance level of $P<0.05$.

\section{RESULTS}

\section{Demographics of Mothers}

Table 4 shows the demographics of the 22 mothers who participated in session 1 and 2. Twelve of the 22 participating mothers self-reported having a different taste perception during pregnancy compared with their taste perception before pregnancy. Changes mentioned by at least 2 mothers included higher liking for sour foods, milky products, or sweet foods, as well as increased taste sensitivity.

\section{Sensory Perception of Human Milk}

In total 54 attributes that describe the odor, flavor, and mouthfeel of human milk were mentioned and selected by the mothers. All attributes mentioned at least $5 \times(\geq 20 \%$ of 22 mothers $)$ are presented in Table 4. The most predominant attributes for human milk (selected at least $10 \times$ ) were neutral, creamy, and sweet smell, sweet flavor, and thin, watery, creamy, and smooth mouthfeel. Bitter and vanilla flavors were also frequently identified in human milk.

\section{Sensory Properties and Composition of Human Fore and Hind Milk}

Sweetness of Fore and Hind Milks. The average sweetness was equivalent to $1.63 \pm 0.59 \mathrm{~g}$ of sucrose $/ 100$ $\mathrm{mL}$ of fore milk and $1.44 \pm 0.56 \mathrm{~g}$ of sucrose/100 $\mathrm{mL}$ of hind milk; the difference was not significant. The mean sweetness averaged over fore and hind milk was 1.53 $\pm 0.58 \mathrm{~g}$ of sucrose $/ 100 \mathrm{~mL}$, with values ranging from 0.14 to $2.86 \mathrm{~g}$ of sucrose $/ 100 \mathrm{~mL}$.

Sensory Properties of Fore and Hind Milks. The taste, flavor, and mouthfeel intensities of fore and hind milk, together with averaged intensities of fore and hind milk, are shown in Table 5. Fore milk tended to be sweeter than hind milk $(P=0.095)$, but this difference was not significant. Bitterness, saltiness, sourness, and umami intensity were not significantly different between fore and hind milks. Hind milk was significantly more intense in vanilla flavor $(P<0.05)$ and creamy odor $(P<0.01)$ compared with fore milk. Sweet odor and milk odor did not significantly differ $(P>0.05)$ between fore and hind milk. Hind milk was significantly creamier $(P<0.001)$, fattier $(P<0.001)$, less watery $(P<0.001)$, and less thin $(P<0.01)$ than fore milk. Smoothness and dryness did not significantly differ between fore and hind milk.

The mixed model analysis that compared the intensities between bitter, sour, umami, and salty (the tastes that were evaluated with the same type of scale) showed no significant differences between the 4 taste intensities. This shows that both fore and hind milk 
Table 5. Mean intensities of basic tastes, creaminess, odor/flavor, and mouthfeel of fore milk, hind milk, and averaged fore and hind milk evaluated by 22 mothers using an unstructured 100-mm line scale anchored at the ends with "like water" ("like milk" for creamy) and "strong"

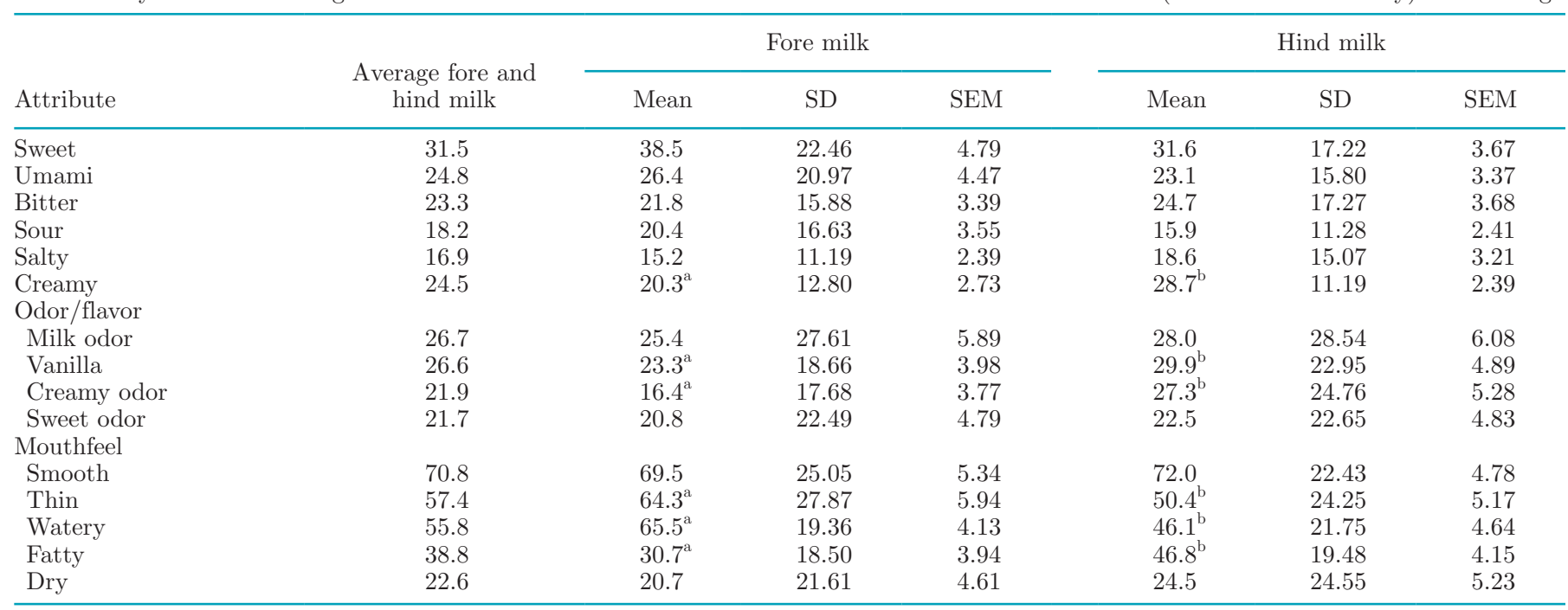

${ }^{\mathrm{a}, \mathrm{b}}$ Means within a row with different superscripts differ $(P<0.05)$.

had similar mean taste intensities across the 4 taste modalities. It should be noted that the intensities of the 4 taste modalities were relatively low, ranging from 15.2 to 26.4 points on the $100-\mathrm{mm}$ scale.

Composition of Fore and Hind Milks. The composition of fore and hind milks is summarized in Table 6. Fore milk was significantly lower in fat, protein, energy, and TS content compared with hind milk. Carbohydrate, total free AA (sum of individual free AA concentrations), and glutamic acid content did not differ significantly $(P>0.05)$ between fore and hind milks.

\section{Correlations}

Between Composition and Sensory Properties of Fore and Hind Milks. Table 7 presents Pearson correlation coefficients between composition and basic tastes and creaminess of fore and hind milks combined.
Creaminess had a significant positive correlation with fat and protein contents, whereas creaminess and carbohydrate content were significantly negatively correlated. Glutamic acid correlated significantly with umami taste and sweet taste correlated with carbohydrate content. When analyzing fore and hind milk separately, a significant correlation was only found between creaminess and protein content in hind milk $(\mathrm{r}=0.55$, $P=0.008)$.

Between Composition of Fore and Hind Milks and Demographics of the Mothers. Table 8 illustrates the correlations between the composition of fore and hind milks combined and selected demographics of the mothers. Carbohydrate content was negatively correlated with age of child and lactation stage and positively correlated with breastfeeding frequency. Conversely, fat and protein content were positively correlated with age of child and lactation stage and negatively correlated with breastfeeding frequency.

Table 6. Composition of fore milk, hind milk, and averaged fore and hind milk

\begin{tabular}{|c|c|c|c|c|c|c|c|}
\hline Component & $\begin{array}{l}\text { Averaged fore and } \\
\text { hind milk }\end{array}$ & \multicolumn{3}{|c|}{ Fore milk } & \multicolumn{3}{|c|}{ Hind milk } \\
\hline Carbohydrates (g/100 mL) & 6.6 & 6.6 & 0.81 & 0.17 & 6.5 & 0.75 & 0.16 \\
\hline Protein $(\mathrm{g} / 100 \mathrm{~mL})$ & 1.1 & $1.0^{\mathrm{a}}$ & 0.24 & 0.05 & $1.2^{\mathrm{b}}$ & 0.24 & 0.05 \\
\hline Energy (kcal/100 mL) & 66.1 & $58.8^{\mathrm{a}}$ & 12.28 & 2.62 & $73.3^{\mathrm{b}}$ & 15.99 & 3.41 \\
\hline $\mathrm{TS}(\mathrm{g} / 100 \mathrm{~mL})$ & 12.0 & $11.2^{\mathrm{a}}$ & 1.51 & 0.32 & $12.8^{\mathrm{b}}$ & 2.01 & 0.43 \\
\hline
\end{tabular}

\footnotetext{
${ }^{\mathrm{a}, \mathrm{b}}$ Means within a row with different superscripts differ $(P<0.05)$.
} 
Table 7. Pearson coefficients for correlations between composition and basic taste and creaminess intensities of human fore and hind milks combined

\begin{tabular}{lccccc}
\hline $\begin{array}{l}\text { Basic taste and } \\
\text { creaminess }\end{array}$ & $\begin{array}{c}\text { Fat } \\
\text { content }\end{array}$ & $\begin{array}{c}\text { Protein } \\
\text { content }\end{array}$ & $\begin{array}{c}\text { Carbohydrate } \\
\text { content }\end{array}$ & $\begin{array}{c}\text { Total free } \\
\text { AA content }\end{array}$ & $\begin{array}{c}\text { Glutamic } \\
\text { acid content }\end{array}$ \\
\hline Sweet & -0.222 & -0.297 & $0.322^{*}$ & 0.020 & 0.004 \\
Umami & 0.116 & -0.175 & 0.190 & 0.178 & $0.395^{*}$ \\
Bitter & 0.128 & 0.045 & -0.039 & -0.165 & 0.160 \\
Sour & 0.184 & 0.106 & -0.031 & 0.101 & 0.121 \\
Salty & 0.014 & 0.043 & -0.034 & 0.076 & -0.093 \\
Creamy & $0.446^{*}$ & $0.542^{*}$ & $-0.400^{*}$ & -0.067 & -0.200 \\
\hline
\end{tabular}

$* P<0.05$.

\section{Bitterness of Mothers' Diet and Human Milks}

The relative bitterness scores (bitterness of food consumed/bitterness of $85 \%$ cacao chocolate) of the most bitter foods (the arbitrary cutoff point was a relative bitterness score $\geq 0.70$, which corresponds to $50 \%$ of the highest relative bitterness score) consumed by the mothers are shown in Table 9, and the mean relative bitterness loads of the main bitter food groups for all mothers combined in Table 10. The bitterest foods belong to the categories of fruits and vegetables, caffeinated beverages, and cheeses; bitterness ranges were high especially for vegetables. We noted a significant positive correlation between the cumulative bitterness load of the mothers' diet during the $24 \mathrm{~h}$ before milk expression and the perceived bitterness of fore milks $(\mathrm{r}=0.45, P=0.034)$. No significant correlation was found between the cumulative bitterness load of the mothers' diet and the perceived bitterness of hind milk $(P>0.05)$.

\section{DISCUSSION}

\section{Sensory Properties of Human Fore and Hind Milk}

The first objective of our study was to determine the sensory characteristics of human fore and hind milk. Human milk as a whole was perceived by the mothers as mainly having neutral, creamy, and sweet smell, sweet flavor, and thin, watery, creamy and smooth mouthfeel.
The creamy smell can probably be attributed to several compounds, such as butan-2,3-dione, (E)-2-octenal, (E,E)-octa-2,4-dienal, and others that are responsible for buttery-like and fatty odor in human milk. The sweet odor could be attributed to compounds such as $\gamma$-decalactone, 2 -aminoacetophenone, $\delta$-dodecalactone, or vanillin, which have been identified in human milk in previous literature (Buettner, 2007).

Vanilla flavor was perceived in the milks of some mothers in our study and also in a previous study (M. Slagter, Danone Nutricia Research, Utrecht, the Netherlands, personal communication), which is a consistent finding with the detection of vanillin in human milks (Buettner, 2007).

Regarding human milk, we concluded that sweetness was the most predominant basic taste. Sweetness was the taste attribute most frequently generated by the mothers (mentioned by 20 out of 22 mothers in session 1). The estimated average sweetness intensity of human milk was equivalent to $1.53 \%$ sucrose in water, which is more than $12 \times$ above the threshold reported by Hoehl et al. (2010) and almost $3 \times$ above the threshold reported by ISO (2011). The mean sweetness intensity found in our study was lower than the value of $2.12 \%$ sucrose in water from a previous study (McDaniel et al., 1989); however, the calculated value is within the range of 1.43 to $2.87 \%$ sucrose equivalency that was obtained by McDaniel et al. (1989). The overall range for sweetness in our study was from 0.14 to $2.86 \%$ sucrose in water, which is wider than the sweetness range in the

Table 8. Pearson coefficients for correlations between composition of human fore and hind milks combined and selected demographics of 22 mothers

\begin{tabular}{lccc}
\hline Variable & $\begin{array}{c}\text { Carbohydrates } \\
\text { content }\end{array}$ & $\begin{array}{c}\text { Fat } \\
\text { content }\end{array}$ & $\begin{array}{c}\text { Protein } \\
\text { content }\end{array}$ \\
\hline Age of mother (yr) & 0.115 & -0.016 & -0.069 \\
Age of breastfeeding child (mo) & $-0.430^{*}$ & $0.457^{*}$ & $0.395^{*}$ \\
Lactation stage (wk) & $-0.380^{*}$ & $0.449^{*}$ & $0.344^{*}$ \\
Breastfeeding frequency (per day) & $0.469^{*}$ & $-0.492^{*}$ & $-0.466^{*}$ \\
Parity (no. children) & 0.030 & 0.012 & 0.194 \\
BMI & -0.250 & 0.027 & 0.090 \\
\hline
\end{tabular}

${ }^{*} P<0.05$. 
Table 9. Relative bitterness scores (bitterness of food consumed/ bitterness of $85 \%$ cacao chocolate) of the most-bitter foods (relative bitterness score $\geq 0.70$ ) consumed by the 22 mothers

\begin{tabular}{lc}
\hline Food & $\begin{array}{c}\text { Relative } \\
\text { bitterness } \\
\text { score }\end{array}$ \\
\hline Celeriac & 1.40 \\
Cappuccino & 1.40 \\
Coffee regular & 1.33 \\
Frozen berries & 1.25 \\
Espresso coffee & 1.13 \\
Mushroom sauce & 1.00 \\
Grapefruit lemonade (squash) & 0.90 \\
Diet cola & 0.83 \\
Brown bread with mayonnaise and smoked salmon & 0.80 \\
Olives & 0.78 \\
Lettuce & 0.78 \\
Brie cheese & 0.78 \\
Basil & 0.78 \\
Latte macchiato & 0.75 \\
Goat cheese & 0.75 \\
Ice tea (Moroccan mint) & 0.71 \\
Forest fruit tea & 0.70 \\
\hline
\end{tabular}

study by McDaniel et al. (1989). The wider sweetness range in our study may be due to the limited training that the participants $(\mathrm{n}=22)$ in our study received in comparison to the trained panel $(\mathrm{n}=6)$ that was used by McDaniel et al. (1989).

As indicated by the mean intensities of the sensory attributes for fore and hind milks averaged, mouthfeel attributes were more dominant than odor attributes. Based on the low intensities of odor attributes, the fact that neutral odor was the most frequently mentioned odor attribute for human milk and also based on the results of the study of Sandgruber et al. (2011), we concluded that human milk does not smell strongly.

Regarding the results for the basic tastes and creaminess of fore and hind milk, the only significant difference we found was for creaminess, with hind milk rated significantly creamier than fore milk. It has been shown that viscosity generates a sensation of thickness (Richardson et al., 1993) and that creaminess is a multimodal attribute consisting of several subattributes, including thick, smooth, fatty, and airy mouthfeel and velvety mouth coating (Weenen et al., 2005). The finding of higher creaminess of hind milk compared with fore milk is consistent with the findings of McDaniel et al. (1989), who showed hind milk is higher in viscosity and mouth-coat than fore milk. Interestingly, hind milk was also higher in creamy odor, suggesting that the higher overall creaminess intensity is not only due to mouthfeel.

Consistent with the McDaniel et al. (1989) study, fore and hind milks were not perceived different in sweetness intensity. Moreover, fore milks were not perceived different from hind milk with regard to bitterness, saltiness, sourness, or umami.

Although it is not the focus of this paper, a comparison with other mammalian milks is interesting. As mentioned in the report of Schiano et al. (2017), relevant attributes for milk products include, among others, sweet aroma, cooked, milk fat, caramelized, metallic, grassy, fruity, cardboard, sweet taste, bitter taste, and viscosity. Although some of these attributes are typical for mammalian milks because they are the result of what cows eat, many attributes, such as sweet, bitter, metallic, creamy, and so on, are shared between human and mammalian milks.

\section{Correlations Between Composition of Human Milks and Sensory Properties and Demographics of the Mothers}

The second aim of our study was to establish relationships between perceived intensities of the basic tastes or creaminess and composition of human milk. Fore milk was significantly lower in fat and protein content compared with hind milk, which is consistent with the findings of McDaniel et al. (1989) as well as with studies of milk of other mammals (Whittlestone, 1953; Aliev, 1961; Atwood and Hartmann, 1992). The mean fat content of fore and hind milk in our study was 2.9 and $4.4 \mathrm{~g} / 100 \mathrm{Ml}$, respectively. In the McDaniel et al. (1989) study, the mean fat content was $1.13 \mathrm{~g} / 100$ $\mathrm{mL}$ for fore milk and $3.21 \mathrm{~g} / 100 \mathrm{~mL}$ for hind milk, but those authors mentioned that these fat contents were considered lower that those found by other studies. Mean protein content in the present study was 1.0 and $1.2 \mathrm{~g} / 100 \mathrm{~mL}$ for fore and hind milks, respectively, which is close to the values of the McDaniel et al. (1989) study (0.98 and $1.15 \mathrm{~g} / 100 \mathrm{~mL}$ for fore and hind milks, respectively). Carbohydrate content of fore and

Table 10. Mean, SD, and range of relative bitterness loads (g) of main bitter food groups for all mothers combined

\begin{tabular}{lcccccrrrr}
\hline Item & Coffee & Tea & Vegetables & Fruit & Chocolate & Meat & Baked $^{1}$ & Cereal & Cheese \\
\hline Mean & 123.4 & 98.5 & 54.2 & 52.8 & 29.4 & 24.5 & 22.2 & 18.2 \\
SD & 60 & 62.4 & 76.5 & 54.4 & 37.7 & 17.8 & 16.7 & 16.8 \\
Minimum & 10.5 & 25 & 1.3 & 1.3 & 3.8 & 2.5 & 1.5 & 1.9 & 1.6 \\
Maximum & 224 & 266.7 & 285.7 & 225 & 100 & 62.5 & 65.6 & 49.2 & 37.5 \\
\hline
\end{tabular}

${ }^{1}$ Baked refers to baked goods, mainly bread and crackers. 
hind milks in our study was found to be 6.6 and 6.5 $\mathrm{g} / 100 \mathrm{~mL}$, respectively, which was slightly lower than the mean lactose content reported by the McDaniel et al. (1989) study $(7.91$ and $7.71 \mathrm{~g} / 100 \mathrm{~mL}$ for fore and hind milk). The finding of the present study, that carbohydrate content does not differ significantly between fore and hind milk, is consistent with a previous study (Mitoulas et al., 2002) but not with the study by McDaniel et al. (1989) study, who reported a significantly higher lactose content in fore milk. Perhaps this difference between our study and the study by McDaniel et al. (1989) is due to the use of different methods.

The total free AA content of fore and hind milks (460 and $446 \mu \mathrm{g} / \mathrm{g}$, respectively) in the present study is within the range of the free amino acid content found in literature (Agostoni et al., 2000; Ferreira, 2003; Chuang et al., 2005).

The relationships between sensory properties and composition of human milk were analyzed in our study. Creaminess, being a multimodal attribute (Weenen et al., 2005; Frøst and Janhøj, 2007) that can be influenced by both fat and protein content (Krzeminski et al., 2011; Sonne et al., 2014), was positively correlated with protein content of hind milk alone and of fore and hind milk combined, and also with fat content in fore and hind milks combined.

A significant correlation was also found between glutamic acid and umami taste, which was expected based on the fact glutamic acid has umami taste (Nishimura and Kato, 1988). However, this result contradicts the study conducted by Yoshida et al. (2014), who did not find a correlation between glutamic acid and umami taste in human milk from breasts inflamed with mastitis. This can possibly be explained by the fact that in mastitic breast tissue permeability is higher and the secretory ability of the mammary glands is reduced (Nguyen and Neville, 1998). Moreover, other components (AA, peptides, nucleotides, and so on) or tastes could have possibly interfered with the perception of umami (Laing et al., 2002).

Our study found a significant correlation between carbohydrate content and perceived sweetness for fore and hind milks combined but not for fore or hind milks separately. In contrast, McDaniel et al. (1989) did not find a significant correlation between sweetness and lactose content. This might be explained by the fact that, in our study, total carbohydrates were determined instead of lactose and a different analytical method was used.

In addition to the relationships between basic tastes and creaminess and composition of human milk, the relationships between demographics of the mothers and composition of human milk were quantified in our study. Fat and protein contents of fore and hind milk combined increase as the age of the child and the lactation stage increase and decrease as the breastfeeding frequency increases. The finding that fat content is positively associated with lactation stage was also found in a previous study (Bachour et al., 2012). In contrast to our finding, Kent et al. (2006) showed that fat content in human milk is not associated with frequency of breastfeeding. However, that study used the creamatocrit method to calculate the fat content $(\mathrm{Lu}-$ cas et al., 1978), which has been shown to have limited precision (Hudson et al., 1979).

\section{Associations Between Bitterness of Mothers' Diet and Bitterness of Their Milk}

The third aim of this study was to assess the relationship between bitterness of the maternal diet and bitterness of human milk. This was achieved by calculating the bitterness load of the foods consumed by the mothers using a 24-h food diary and correlating it with the bitterness intensity that the mothers perceived for fore and hind milks. Consistent with earlier studies showing that the maternal diet influences the sensory characteristics of human milk (Mennella, 1995; Mennella and Beauchamp, 1991a,b, 1999; M. Slagter, Danone Nutricia Research, Utrecht, the Netherlands, personal communication) and showing that bitter tasting alkaloids can be transferred from the maternal diet to milk (Aresta et al., 2005), a significant correlation was found between the bitterness of the diet consumed before lactation and the perceived bitterness intensity of fore milk. However, the bitterness load was highly variable and the correlation with a linear function was significant but only moderately strong $(\mathrm{r}=0.45, P$ $=0.034)$. This is likely due to the limited training of mothers in bitterness assessment of their milk and diet as well the relatively low number of participants. Using bitterness density (bitterness load/1,000 kcal) rather than bitterness load may possibly also improve the correlation (Lease et al., 2016).

The reason why the bitterness of the mother's diet is correlated with the bitterness of fore milk and not with that of hind milk is difficult to explain. It could be due to the watery nature of fore milk, due to the different way and time of formation and expression of the 2 types of milk in the mammary gland or due to a masking of bitterness in hind milk. This masking effect could be due to the higher fat content of hind milk, as it has been shown that several fatty acids present in human milk can mask the bitterness of bitter solutions (Ley, 2008).

To assist mothers with the bitterness scoring of the foods consumed, an $85 \%$ cacao chocolate bar was provided to use as a reference to make the sensory method 
more precise. An alternative we considered was the use of sensory databases to calculate the bitterness load from the mothers' diet; however, such databases do not contain all foods and combinations of foods, such as a sandwich. Therefore, for the specific purpose of our study, the self-report method was considered more suitable. Recently, a more elaborate sensory diet database has become available (Teo et al., 2018) that would make it possible to get more accurate assessments of bitterness loads, which enable a bitterness assessment of the maternal diet that is not dependent on mothers' assessment of their diet.

The finding that the bitterness of the mother's diet is correlated with the bitterness perception of human fore milk is interesting, as it may add support to the recommendations for a high vegetable consumption by lactating mothers (WHO, 2011). However, adding bitterness to the diet of lactating mothers in general should not be a recommendation, as several bioactive compounds from bitter foods and drinks that should be avoided or limited during breastfeeding (e.g., those containing caffeine, alcoholic beverages, and so on) can be transferred to human milk (Mennella and Beauchamp, 1991b; Aresta et al., 2005). Consumption of (bitter) vegetables during breastfeeding should be recommended.

\section{Strengths and Weaknesses}

The current study is, to our knowledge, the first to have found a relationship between the bitterness load of the mother's diet and the bitterness of her milk, suggesting that bitter taste can be transferred through fresh human milk. This finding adds to the existing knowledge about possible contributing factors to flavor learning in early life. The fact that the food diary was kept by mothers between session 1 and session 2 could have potentially biased the sensory assessment of mothers in session 2, as mothers were asked in the diary to focus on bitterness scoring of their diet. However, the qualitative sensory description of human milk in session 1 was not biased in this way.

The present study is also the first study to have developed a protocol that can be used to obtain detailed information about the sensory profile of fresh human milk and the sensory differences of fore and hind milk from mothers previously unfamiliar with sensory evaluation. The present study offers a more extended sensory description of fresh human milk including the sensory evaluation of several different sensory modalities (tastes, odor, flavor, texture, or mouthfeel) using a larger number of attributes. Using the average sweetness value of the McDaniel et al. (1989) study as the middle sweetness intensity reference solution has allowed for more accurate data, and using the equi-intensity refer- ences for bitter, umami, sour, and salty tastes from the Spectrum method has allowed for comparable data regarding these basic taste intensities of fore and hind milk.

However, we identified several limitations to this study. The self-assessment method used for the sensory evaluation of human milk by mothers could be subject to sensory adaptation bias, meaning that mothers could show a decreased responsiveness of odor or flavor stimulation if they repeatedly smell or taste their own milk. Foods were assessed as a whole, which means that the bitterness of individual components could have been masked by the taste of others. Moreover, the training on the self-assessment of the sensory attribute intensities was limited and the self-assessment was not performed in replicate due to sample amount and time constraints. The only way to do replications would be to collect more milk per sample and divide the sample into 2 portions that then could be evaluated separately. However, from informal discussions with women before the study, it became clear that expressing $2 \times 50$ to 60 $\mathrm{mL}$ (fore and hind milk) would be too much of a burden for many women, which would make recruitment very difficult. We therefore decided not to include replicate assessments in the study. During the training session, some mothers incorrectly ranked the intensities of some reference samples in the ranking task, especially the bitter and creamy references. This could be due to the mothers' insensitivity to the bitter tastant or creamy taste and texture or due to the lack of extensive training.

To address the methodological issues, a trained panel could potentially be used instead of the mothers evaluating their own milk. However, for this, all human milks collected should first be tested for microbiological safety against lipid-enveloped viruses (human immunodeficiency virus or hepatitis A, B, and C) and bacteria (Escherichia coli, Staphylococcus aureus, and Streptococcus agalactiae) that represent a main concern for the use of unpasteurized human milk (Terpstra et al., 2007). In addition, the storage conditions of the samples should be carefully considered, as it has been shown that cooling human milk to $4^{\circ} \mathrm{C}$ (Spitzer et al., 2013) and even freezing at $-19^{\circ} \mathrm{C}$ can lead to sensory deterioration by the formation of metallic and fishy odor (Spitzer et al., 2010); freezing at $-80^{\circ} \mathrm{C}$ was found to be sufficient to prevent odor formation during storage (Sandgruber et al., 2011). For these reasons, selfassessment of freshly expressed human milk by mothers was considered more appropriate in our study to avoid storing cooled fresh human milk, as was done by McDaniel et al. (1989).

Alternatively, the self-assessment method could be improved by adding replicates and improving the 
training. Attribute definitions could be provided for the sensory attributes of human milk other than the basic tastes, so that all participants would score the attributes in a more consistent way. Replicate measurements would require that more milk be collected per sample. The limited quantity issue could be partially overcome by not including chemical measurements or not including both fore and hind milk samples. Assessment of the effect of diet on maternal milk could possibly be improved by applying sensory density instead of sensory load, using a larger sample, and by an experimental instead of observational approach.

\section{CONCLUSIONS}

We described the sensory properties of human milk based on a qualitative profile by 22 mothers. Perceptible sensory, as well as analytical, differences were highlighted between fore and hind milk. We found correlations between creaminess and protein and fat content in fore and hind milk combined, carbohydrate content and sweetness, and between glutamic acid and umami taste. The bitterness load of the maternal diet in the 24-h period before milk expression is moderately correlated with the bitterness of fore milk but not of hind milk. We concluded that the consumption of bitter foods in the maternal diet may influence the bitterness of human (fore) milk. This study contributes to the notion that breastfeeding can help children to learn to such as vegetables, and hence develop healthier food preferences.

\section{ACKNOWLEDGMENTS}

The authors express sincere appreciation to the following people for their support and guidance: Michael O' Mahony (University of California, Davis); Benoît Rousseau (The Institute of Perception); Elleny Balder, Mirjam Slagter, Michel Rogeaux, Frederike Sieders, Eline Voogd, Gerrit Witte, Jose Scheer and Gabriel Thomassen (Nutricia Research). Gratitude is also extended to Thomas Schoonbrood, Faradina Helmi (Nutricia Research), Gerda Holleman (University of Applied Sciences Utrecht, Utrecht, the Netherlands) and Pieter and Martin Punter (OP\&P Product Research, Utrecht, the Netherlands) for supporting the recruitment of participants.

\section{REFERENCES}

Agostoni, C., B. Carratù, C. Boniglia, A. M. Lammardo, E. Riva, and E. Sanzini. 2000. Free glutamine and glutamic acid increase in human milk through a three-month lactation period. J. Pediatr. Gastroenterol. Nutr. 31:508-512.
Aliev, M. G. 1961. Variations in secretion of milk fat and protein in the course of a lactation by buffaloes. Izvestiya Akademii Nauk Azerbaidzhanskoi SSR. Seriya Biologicheskikh i Meditsinskikh Nauk. 10:127-137.

Alvarez, V. B. 2008. Fluid milk and cream products. Pages 73-133 in The Sensory Evaluation of Dairy Products. Springer, New York, NY.

Ames, B. N., M. Profet, and L. S. Gold. 1990. Dietary pesticides (99.99\% all natural). Proc. Natl. Acad. Sci. USA 87:7777-7781.

Aresta, A., F. Palmisano, and C. G. Zambonin. 2005. Simultaneous determination of caffeine, theobromine, theophylline, paraxanthine and nicotine in human milk by liquid chromatography with diode array UV detection. Food Chem. 93:177-181.

Atwood, C. S., and P. Hartmann. 1992. Collection of fore and hind milk from the sow and the changes in milk composition during suckling. J. Dairy Res. 59:287-298.

Babcock, C. 1938. Feed flavors in milk and milk products. J. Dairy Sci. 21:661-668

Bachour, P., R. Yafawi, F. Jaber, E. Choueiri, and Z. Abdel-Razzak. 2012. Effects of smoking, mother's age, body mass index, and parity number on lipid, protein, and secretory immunoglobulin A concentrations of human milk. Breastfeed. Med. 7:179-188.

Ballard, O., and A. L. Morrow. 2013. Human milk composition: Nutrients and bioactive factors. Pediatr. Clin. North Am. 60:49-74.

Bradley, R. 1757. General Treatise of Agriculture, Both Philosophical and Practical. Gale ECCO.

Brown, P., and R. A. Hartwick. 1988. High Performance Liquid Chromatography. John Wiley and Sons Inc., New York, NY.

Buettner, A. 2007. A selective and sensitive approach to characterize odour-active and volatile constituents in small-scale human milk samples. Flavour Fragrance J. 22:465-473.

CalorieLab. 2016. The CalorieLab Nutrition Database. Henderson, NV.

Chuang, C. K., S. P. Lin, H. C. Lee, T. J. Wang, Y. S. Shih, F. Y Huang, and C. Y. Yeung. 2005. Free amino acids in full-term and pre-term human milk and infant formula. J. Pediatr. Gastroenterol. Nutr. 40:496-500.

Cooke, L., and A. Fildes. 2011. The impact of flavour exposure in utero and during milk feeding on food acceptance at weaning and beyond. Appetite 57:808-811.

de Wild, V. W., G. Jager, A. Olsen, V. Costarelli, E. Boer, and G. Zeinstra. 2018. Breast-feeding duration and child eating characteristics in relation to later vegetable intake in 2-6-year-old children in ten studies throughout Europe. Public Health Nutr. 21:2230-2238.

Deterre, S., J. Delarue, C. Innocent, and P. Giampaoli. 2012. Evaluation of bitterness intensity of citrus products by an untrained panel using relative-to-reference rating. Food Sci. Nutr. 3:80.

Drewnowski, A. 1989. Sensory preferences for fat and sugar in adolescence and adult life. Ann. N. Y. Acad. Sci. 561:243-250.

Drewnowski, A. 1997. Taste preferences and food intake. Annu. Rev. Nutr. 17:237-253.

Drewnowski, A. 2000. Sensory control of energy density at different life stages. Proc. Nutr. Soc. 59:239-244.

Drewnowski, A., and C. Gomez-Carneros. 2000. Bitter taste, phytonutrients, and the consumer: A review. Am. J. Clin. Nutr. 72:14241435.

Ferreira, I. M. 2003. Quantification of non-protein nitrogen components of infant formulae and follow-up milks: comparison with cows' and human milk. Br. J. Nutr. 90:127-133.

Fromm, H. I., and K. J. Boor. 2004. Characterization of Pasteurized Fluid Milk Shelf-life Attributes. J. Food Sci. 69:207-214.

Frøst, M. B., and T. Janhøj. 2007. Understanding creaminess. Int. Dairy J. 17:1298-1311.

Fusch, G., N. Rochow, A. Choi, S. Fusch, S. Poeschl, A. O. Ubah, S. Y. Lee, P. Raja, and C. Fusch. 2015. Rapid measurement of macronutrients in breast milk: How reliable are infrared milk analyzers? Clin. Nutr. 34:465-476.

Galloway, A. T., Y. Lee, and L. L. Birch. 2003. Predictors and consequences of food neophobia and pickiness in young girls. J. Am. Diet. Assoc. 103:692-698. 
Goatcher, W. D., and D. C. Church. 1970. Taste responses in ruminants. 4. Reactions of pygmy goats, normal goats, sheep and cattle to acetic acid and quinine hydrochloride. J. Anim. Sci. 31:373-382.

Hausner, H., W. L. Bredie, C. Mølgaard, M. A. Petersen, and P. Møller. 2008. Differential transfer of dietary flavour compounds into human breast milk. Physiol. Behav. 95:118-124.

Hoehl, K., G. U. Schoenberger, and M. Busch-Stockfisch. 2010. Water quality and taste sensitivity for basic tastes and metallic sensation. Food Qual. Prefer. 21:243-249.

Hudson, G. J., H. Gerber, and P. John. 1979. Creamatocrit procedure versus triglyceride analysis: a comparison of methods for the determination of human milk fat in epidemiological studies. J. Hum. Nutr. 33:283-287.

ISO. 2011. ISO 3972:2011 Sensory Analysis- Methodology- Method of investigating sensitivity of taste. International Organization for Standardization (ISO), Geneva, Switzerland.

Kent, J. C., L. R. Mitoulas, M. D. Cregan, D. T. Ramsay, D. A. Doherty, and P. E. Hartmann. 2006. Volume and frequency of breastfeedings and fat content of breast milk throughout the day. Pediatrics 117:e387-395.

Kirsch, F., K. Horst, W. Röhrig, M. Rychlik, and A. Buettner. 2013. Tracing metabolite profiles in human milk: Studies on the odourant 1,8-cineole transferred into breast milk after oral intake. Metabolomics 9:483-496.

Krzeminski, A., K. Großhable, and J. Hinrichs. 2011. Structural properties of stirred yoghurt as influenced by whey proteins. LWT Food Sci. Technol. 44:2134-2140.

Laing, D. G., C. Link, A. L. Jinks, and I. Hutchinson. 2002. The limited capacity of humans to identify the components of taste mixtures and taste-odour mixtures. Perception 31:617-635.

Lease, H., G. A. Hendrie, A. A. M. Poelman, C. Delahunty, and D. N. Cox. 2016. A sensory-diet database: A tool to characterise the sensory qualities of diets. Food Qual. Prefer. 49:20-32.

Lee, A. P., D. M. Barbano, and M. A. Drake. 2017. The influence of ultra-pasteurization by indirect heating versus direct steam injection on skim and 2\% fat milks. J. Dairy Sci. 100:1688-1701.

Ley, J. P. 2008. Masking bitter taste by molecules. Chemosens. Percept. 1:58-77.

Lien, N., L. A. Lytle, and K. I. Klepp. 2001. Stability in consumption of fruit, vegetables, and sugary foods in a cohort from age 14 to age 21. Prev. Med. 33:217-226.

Lucas, A., J. Gibbs, R. Lyster, and J. Baum. 1978. Creamatocrit: Simple clinical technique for estimating fat concentration and energy value of human milk. BMJ 1:1018-1020.

Lytle, L. A., S. Seifert, J. Greenstein, and P. McGovern. 2000. How do children's eating patterns and food choices change over time? Results from a cohort study. Am. J. Health Promot. 14:222-228.

MacGibbon, A. K. H., and M. W. Taylor. 2006. Composition and structure of bovine milk lipids. Pages 1-42 in Advanced Dairy Chemistry, Volume 2: Lipids. Springer, Boston, MA.

Martin, C., A. Maire, C. Chabanet, and S. Issanchou. 2015. Equiintensity across the Spectrum taste scales. Food Qual. Prefer. 44:75-83

McCarthy, K. S., K. Lopetcharat, and M. A. Drake. 2017. Milk fat threshold determination and the effect of milk fat content on consumer preference for fluid milk. J. Dairy Sci. 100:1702-1711.

McDaniel, M. R., E. Barker, and C. Lederer. 1989. Sensory characterization of human milk. J. Dairy Sci. 72:1149-1158.

Mennella, J. A. 1995. Mother's milk: A medium for early flavor experiences. J. Hum. Lact. 11:39-45.

Mennella, J. A. 2007. The chemical senses and the development of flavor preferences in humans. Pages 403-414 in Textbook on Human Lactation. Hale Publishing, Plano, TX.

Mennella, J. A., and G. K. Beauchamp. 1991a. Maternal diet alters the sensory qualities of human milk and the nursling's behavior. Pediatrics 88:737-744.

Mennella, J. A., and G. K. Beauchamp. 1991b. The transfer of alcohol to human milk: Effects on flavor and the infant's behavior. N. Engl. J. Med. 325:981-985.
Mennella, J. A., and G. K. Beauchamp. 1996a. The human infants' response to vanilla flavors in mother's milk and formula. Infant Behav. Dev. 19:13-19.

Mennella, J. A., and G. K. Beauchamp. 1996b. Developmental changes in the acceptance of protein hydrolysate formula. J. Dev. Behav. Pediatr. 17:386-391.

Mennella, J. A., and G. K. Beauchamp. 1998. Smoking and the flavor of breast milk. N. Engl. J. Med. 339:1559-1560.

Mennella, J. A., and G. K. Beauchamp. 1999. Experience with a flavor in mother's milk modifies the infant's acceptance of flavored cereal. Dev. Psychobiol. 35:197-203.

Mennella, J. A., L. M. Daniels, and A. R. Reiter. 2017. Learning to like vegetables during breastfeeding: A randomized clinical trial of lactating mothers and infants. Am. J. Clin. Nutr. 106:67-76.

Mennella, J. A., C. P. Jagnow, and G. K. Beauchamp. 2001. Prenatal and postnatal flavor learning by human infants. Pediatrics 107:E88.

Mitoulas, L. R., J. C. Kent, D. B. Cox, R. A. Owens, J. L. Sherriff, and P. E. Hartmann. 2002. Variation in fat, lactose and protein in human milk over $24 \mathrm{~h}$ and throughout the first year of lactation. Br. J. Nutr. 88:29-37.

Nehring, I., T. Kostka, R. von Kries, and E. A. Rehfuess. 2015. Impacts of in utero and early infant taste experiences on later taste acceptance: A systematic review. J. Nutr. 145:1271-1279.

Nguyen, D. A. D., and M. C. Neville. 1998. Tight junction regulation in the mammary gland. J. Mammary Gland Biol. Neoplasia $3: 233-246$.

Nicklaus, S., V. Boggio, C. Chabanet, and S. Issanchou. 2005. A prospective study of food variety seeking in childhood, adolescence and early adult life. Appetite 44:289-297.

Nishimura, T., and H. Kato. 1988. Taste of free amino acids and peptides. Food Rev. Int. 4:175-194.

Palmquist, D. L., A. D. Beaulieu, and D. M. Barbano. 1993. Feed and animal factors influencing milk fat composition. J. Dairy Sci. 76:1753-1771.

Richardson, N. J., D. A. Booth, and N. L. Stanley. 1993. Effect of homogenization and fat content on oral perception of low and high viscosity model creams. J. Sens. Stud. 8:133-143.

Sandgruber, S., D. Much, U. Amann-Gassner, H. Hauner, and A. Buettner. 2011. Sensory and molecular characterisation of human milk odour profiles after maternal fish oil supplementation during pregnancy and breastfeeding. Food Chem. 128:485-494.

Schiano, A. N., W. S. Harwood, and M. A. Drake. 2017. A 100-year review: Sensory analysis of milk. J. Dairy Sci. 100:9966-9986.

Shipe, W., R. Bassette, D. Deane, W. Dunkley, E. Hammond, W. Harper, D. H. Kleyn, M. E. Morgan, J. H. Nelson, and R. A. Scanlan. 1978. Off flavors of milk: Nomenclature, standards, and bibliography. J. Dairy Sci. 61:855-869.

Skinner, J. D., B. R. Carruth, W. Bounds, and P. J. Ziegler. 2002. Children's food preferences: A longitudinal analysis. J. Am. Diet. Assoc. 102:1638-1647.

Sonne, A., M. Busch-Stockfisch, J. Weiss, and J. Hinrichs. 2014. Improved mapping of in-mouth creaminess of semi-solid dairy products by combining rheology, particle size, and tribology data. LWT Food Sci. Technol. 59:342-347.

Spitzer, J., S. Doucet, and A. Buettner. 2010. The influence of storage conditions on flavour changes in human milk. Food Qual. Prefer. 21:998-1007.

Spitzer, J., K. Klos, and A. Buettner. 2013. Monitoring aroma changes during human milk storage at +4 degrees $\mathrm{C}$ by sensory and quantification experiments. Clin. Nutr. 32:1036-1042.

Stoer, N. L., and H. T. Lawless. 1993. Comparison of single product scaling and relative-to-reference scaling in sensory evaluation of dairy products. J. Sens. Stud. 8:257-270.

Sullivan, S. A., and L. L. Birch. 1994. Infant dietary experience and acceptance of solid foods. Pediatrics 93:271-277.

Sutton, J. D. 1989. Altering milk composition by feeding. J. Dairy Sci. 72:2801-2814

Teo, P. S., A. W. B. van Langeveld, K. Pol, E. Siebelink, C. de Graaf, C. Martin, S. Issanchou, S. W. Yan, and M. Mars. 2018. Training 
of a Dutch and Malaysian sensory panel to assess intensities of basic tastes and fat sensation of commonly consumed foods. Food Qual. Prefer. 65:49-59.

Terpstra, F. G., D. J. Rechtman, M. L. Lee, K. V. Hoeij, H. Berg, F. A. V. Engelenberg, and A. B. V. T. Wout. 2007. Antimicrobial and antiviral effect of high-temperature short-time (HTST) pasteurization applied to human milk. Breastfeed. Med. 2:27-33.

Toso, B., G. Procida, and B. Stefanon. 2002. Determination of volatile compounds in cows' milk using headspace GC-MS. J. Dairy Res. 69:569-577.

van Rossum, C. T., E. J. De Boer, and M. C. Ocke. 2009. Dutch national food consumption survey-Young children 2005/2006. Ann. Nutr. Metab. 55:521-522.

van Ruth, S. M., V. Floris, S. Fayoux, and M. Shine. 2006. Characterisation of the flavour of infant formulas by instrumental and sensory analysis. Dev. Food Sci. 43:493-496. https://doi.org/10.1016/ S0167-4501(06)80116-0.

Weenen, H., R. Jellema, and R. De Wijk. 2005. Sensory sub-attributes of creamy mouthfeel in commercial mayonnaises, custard desserts and sauces. Food Qual. Prefer. 16:163-170.
Whittlestone, W. G. 1953. Variations in the fat content of milk throughout the milking process. J. Dairy Res. 20:146-153.

WHO. 2011. Healthy Eating During Pregancy and Breastfeeding (booklet for mothers). Accessed Feb. 2017. http://www.euro.who .int/__data/assets/pdf_file/0020/120296/E73182.pdf.

WHO/FAO. 2002. Diet, Nutrition and the Prevention of Chronic Diseases: Report of a JOINT WHO/FAO Expert Consultation. World Health Organization, Geneva, Switzerland.

Yamaguchi, S. 1998. Basic properties of umami and its effects on food flavor. Food Rev. Int. 14:139-176.

Yngve, A., A. Wolf, E. Poortvliet, I. Elmadfa, J. Brug, B. Ehrenblad, B. Franchini, J. Haraldsdóttir, R. Krølner, L. Maes, C. Pérez-Rodrigo, M. Sjostrom, I. Thórsdóttir, and K. I. Klepp. 2005. Fruit and vegetable intake in a sample of 11-year-old children in 9 European countries: The pro children cross-sectional survey. Ann. Nutr. Metab. 49:236-245.

Yoshida, M., H. Shinohara, T. Sugiyama, M. Kumagai, H. Muto, and H. Kodama. 2014. Taste of milk from inflamed breasts of breastfeeding mothers with mastitis evaluated using a taste sensor. Breastfeed. Med. 9:92-97. 